\title{
A BUSINESS PLAN FOR “LAHANOKIPOI” AREA OF THESSALONIKI
}

\author{
Vasiliki BASDEKIDOU \\ Dept. of Economic - Aristotle University of Thessaloniki
}

\begin{abstract}
This paper is about an economic investigation in order to analyze the existing situation of Lahanokipoi landscape and the possibilities that can come out when exploring it., starting by writing down the existing business companies and industries, the value of landscape by using economic ratios and the prospective that can come out. The Lahanokipoi area covers a big part of old industries that are no longer in use and there is very low developement, which suggests that there could be a total reconstruction of landscape, either by building a bisiness park or a business center with all kinds of facilities and parks. The project suggests a new model that is economic stable and introduces not only the economic and business developement that can be achieved but also the enviromental and architectural structure that can maximize the value of landscape. It is the firsttimeinliteraturethatwehavealandscapeeconomic and architectural analysis in this part of the city and so the contribution of this paper is of vital importance.The fact that there is a low construction in the area clearly shows the perspective of future developement. The proposed methodology is of interest for architects, civil engineers, enviromental analysts, businessmen, public sector representatives, local authorities, economologists and many others.
\end{abstract}

Keywords: Landscape ; Business plan; Business park; Construction; Environment

\section{Introduction}

The study of Lahanokipoi area started due to a university project that has been given from the Municipality of Thessaloniki and intends to analyze the objective value of the area in order to create a full-organized bussiness park that will increase the value of landscape and of the whole area[1]. It is of vital importance because this area has been deserted up to a point and needs to be rebuilt in order to attract the interest of the ctizens. This area has already attracted many scientists such as architects, civil engineers and economologists, who have been occupied with various suggestions for it.

Lahanokipoi area is situated in the west entry of Thessaloniki city, is close to the port and at the moment there are a few businesses that function there, some of them are new but most of them are old and count many years of function. The area is now at "crisis", as it's said, which has given the motivation to local authorities to restudy the perspectives of the specificareaandtoorganizeaprojecttoexplorethe landscape [2].

It is actually amazing the fact that the area could be transformed into a second metropolitan center of the city, due to it's priviledged location. It combines all the nessesary conditions for such a thing. The perspectives are many and the authorities have finallyunderstoodit.

This investigation intends to present all the possibilities that Lahanokipoi area can show and it suggests solutions that can be really usefull [3]. The firststepistoshow the landscape right now, how many companies are there and which of them have a real reason to be there. How many buildings are deserted and how dangerous it can be to even consider walking there during day time. How the garbage and the dirt ruin all the atmosphere and make it impossible for someone even to stand there, imagine working there [4].

The second step is to give some details of the existing suggestions, compare the advantages and disadvantages of these suggestions by using SWOT analysis (Strengths, Weaknesses, Opportunities, Threats) and end up to the best suggestion [5]. Finally, the third step presents a 
fullfilledsuggestionofabusinessparkwithallthe nesessary facilities, that proves to be the best choice for the area and analyzes the importance that could have for the city [6].

\section{The Project (Analysis)}

Lahanokipoi area, as it is reffered above, is situated in the west side of the city, near the port and the center. There are many businesses that are founded and function in the wide zone of the area, such as business centers, technical companies, small entreprizes, ship companies, importexport companies, advertisement offices, amusementclubsandmanyothers.Someofthemaresituatedinnew,modern buildings, some others, usually the olders, in older buildings [2]. The area is characterized by the coexistance of old and ugly buildings with new and more priviledged ones.

The general idea is to create a business park where a big number of those businesses or all of them could be situated in similar and more ellegant buildings, that would express the style and the image of those companies, according to the services that each one of them provides. It would be extremely interesting if we could gather in the same business park all kinds of businesses with different objects each one, and in different kinds of buildings. It could be an architectural revolution for the city and could also attract many visitors, instead of only the citizens themselves [5]. This could also be very helpful, because it would provide a sort of identity for those businesses and people could identify at once the kind of businesses that each building represents.

This of course, is not at all easy to acheive. There are many key factors that need to be consider, such as the number of businesses that a business center could have, the object of the business and the reasons why a company should move to a business center, the benefitsthatitprovides, theareathatitshouldbesituated,howclose to the city and the objective value of landscape right now [6]. It is an endless catalogue and it needs the cooperation of many scientists and researchers in order to acheive the best possible result with the maximum benefit.

Right now the situation is considered to be rather wild or even dangerous. This is because the area lacks of control and after daytime is dangerous even walking there on foot. The suggestion is to create a business center that would increase mobility and trafficintheareaandwouldattractmorepeopleinordertominimizethedanger.There are three issues that need to be considered here. First the exact location of the business park, second the definitionofnecessaryandbasicinfrastructureandfacilities of the business park and third the budget that such a plan needs. We are going to analyze each issue seperetely.

\subsection{Location}

Especially the term "location" refers to the geographical placement of the space in which the business park will take place in relation to the characteristics of the area that will be chosen [4].

Lahanokipoi area is selected because it combines all the below characteristics in addition to the necessity of it's immediate exploration.

Restrictive factors such as the incorporation of the site in the urban-planning, the institutional and property-ownership regime, the value of the land etc will also be studied. An additional important restrictive factor is the enviromental impact of the project.

It is evident that "site" and "infrastructure" are interrelated. Indicate factors that relate the two are:

-availability and value of the land

-accessibility and connection with highways or central roads, distance from the port, etc.

-enviromental impact

-availability of power networks and telecommunications 
It is alse nesessary to be considered:

- the geo-morphological characteristics, land-usages, sensitive and protected areas,

- transportation accessibility, incorporation in the urban-planning,

- developement trends of the area and architectural innovation.

\subsection{Definitionofnecessaryandbasicinfrastructureandfacilities}

In this issue we need to consider the necessary natural and enviromental infrastrusture such as water-sewage, waste management, etc[2]. Also the nesessary technology and telecommunication infrastructure that will make the business park even more priviledged and attracted.

Most importantly is the parking space that will be designed in order to solve the big parking problem of the area and therefore will attract even more businesses.

It could also be wise to include some conference spaces that will gather bussinessmen from abroad and will increase in such way motivation and innovation in the area.

Finally, allocation of open-air spaces such as open-air stands, rest areas, etc will be equally usefull and necessary in addition to the security and monitory systems that will make the area safe including fencing.

\subsection{Budgeting}

Before the exact estimation of the cost of such a business park it is important to start a premarketing analysis in order to examine the business trends of the area. This is possible by creating a small questionnaire that will be handed to businessmen of the area but also to other bussinessmen of the city in order to understand their future moves and to examine their intention to move to this business park[3].

The budget of the park is interrelated with the objective cost of landscape and it's accessibility. This is now under examination and by the end of the year a fullfilledbudget prediction shall be ready.

A SWOT analysis or a cost benefitanalysiswillmakethisproposalevenmoreclear.

\section{SWOT analysis of Lahanokipoi area}

SWOT analysis is an important instrument in order to evaluate the right exploration of landscape and this study presents all the benefitsforcreatingthisbusiness park in Lahanokipoi area [3].

There is also the need to provide the economic ratios of the objective value of landscape in order to estimate the benefitsthatcancomeoutbyexploringthearea.These ratios are stable and adjustable, according to the position of landscape and they will provide an exact prediction for budgeting.

\subsection{Strengths:}

-Location of the area (near the center of the city, accessible to the sea and the port, business area, free unexplored space and landscape)

-developement trends, since there is already business infrastructure in the wide area

-there is no other business park so it is an important innovation for the city

-free parking space

-accessibility to the center and other businesses

-better business enviroment

-better access and parking spaces 
-better accomodation and facilities

-architectural innovation

-better security of the area - increase of safety

-approriate exploration of landscape

\subsection{Weaknesses}

-Difficultyinestimatingtheexactlandevaluation,becausethereisacomplexityin landscape ownership -difficultyinconvincingthestate(municipality)forimmediatefunding(bereaucracy)in order to explore landscape

-several delays of the project

\subsection{Opportunities}

-New business oppurtunities for young businessmen

-opportunities for expanding the already existing businesses

-opportunity for creation of business clusters

\subsection{Threats}

- Enviromental organizations that might be against it 
- small older businesses will close down or be ruined

- historical value of the buildings will be destroyed

\section{Results, Discussion and Future Perspectives}

This project intents to show the dynamics that Lahanokipoi area presents and with the right exploration it could lead to important and beneficialperspectives.By accomplishing the exploration of landscape and creating a full- planned and well organized business park, small and big companies could gather all together in a friendly and healthy enviroment, just a bit away from the noise of the city and could function in the best possible way [2]. The job enviroment is one of the most nesessary things when it comes to job selection and it could play a very important role in a company's choice to move.

The selection of the appropriate location is the firststep[4].The second stepis to choose the architectural characteristics of the buildings and the facilities that the park could offer, after examining the market situation and predicting the business preferences [5].This could happen with the cooperation of a team of scientist such as architects, civil engineers, economologists, laywers, marketeers, analysts, managers and also enviromental scientists.

It is proved above that with the right organization and cooperation this business park will increase the business and developement trends of the area and will motivate many businessmen. Additionally, it could lead to a great architectural innovation for the city and attract many visitors. 


\section{Bibliography:}

[1] V.Choudhury, Strategic choices in the developement of inter-organizational information systems, Information Systems Research 8(1997)(1), pp. 1-24.

[2] L.Applegate, W.McFarlan and J.McKenney, Corporate Information Systems Management: Text and Cases (fifth.ed.),Irwin/McGraw-Hill,NewYork(1999).

[3] S.Kaplan and M. Sawhney, E-Hubs: the new B2B marketplaces, Harvard Business Review (2000), pp. 98-103.

[4] K.Kyung Kyu and U.Narayan S., Information transfer in B2B procurement:an empirical analysis and measurement (2004).

[5] P.Bentler, EQS Structural Equations Program Manual, Multivariate Software, Encino, CA (1995).

[6] F.Bergeron and L.Raymond, The advantage of electronic data interchange, Database 23 (1992) (4), pp.19-31. 